\title{
Electrosynthesis and Characterization of Polypyrrole/Cashew Gum Composite Grown on Gold Surface in Aqueous Medium
}

\author{
Rômulo A. O. Castro ${ }^{1}$, Rubênia S. Monte ${ }^{1}$, Luana G. Mendes ${ }^{1}$, Roselayne F. Furtado ${ }^{2 *}$, \\ Angelo R. A. Silva ${ }^{3}$, Atanu Biswas ${ }^{4}$, Huai N. Cheng ${ }^{5}$, Carlucio R. Alves ${ }^{1 *}$ \\ ${ }^{1}$ Department of Chemistry, State University of Ceara, 1700 Dr. Silas Munguba Avenue, Fortaleza-CE \\ 60740-903, Brazil. \\ ${ }^{2}$ Embrapa Tropical Agroindustry, 2270 Sara Mesquitaalves Street, Fortaleza-CE 60511-110, Brazil. \\ ${ }^{3}$ Atomic Force Microscopy Laboratory, University of Fortaleza, 1321 Washington Soares Avenue, \\ Fortaleza-CE 60811-905, Brazil. \\ ${ }^{4}$ USDA Agricultural Research Service, National Center for Agricultural Utilization Research, 1815 \\ North University Street, Peoria, Illinois 61604, USA. \\ ${ }^{5}$ USDA Agricultural Research Service, Southern Regional Research Center, 1100 Robert E. Lee \\ Blvd., New Orleans, Louisiana 70124, USA. \\ *E-mail: alvescr@yahoo.com, roselayne.furtado@embrapa.br
}

doi: $10.20964 / 2017.01 .16$

Received: 15 July 2016 / Accepted: 29 October 2016 / Published: 12 December 2016

One of the current trends in the design of electronic materials is the use of agro-based, renewable materials with a minimum amount of toxic substances present. Consistent with this trend, we investigated the electrosynthesis and the electrochemical, morphological, and topographical characteristics of a novel conducting polypyrrole/cashew gum (PPy/CG) composite. The composite films were grown on gold surface by cyclic voltammetry and chronoamperometry in an aqueous medium. They were characterized using FTIR-ATR, SEM, AFM and cyclic voltammetry. The composites gave evidence of the incorporation of CG in PPy film, which had a granular and nodular morphology with grain size ranging from 0.7 to $2.0 \mu \mathrm{m}$. Moreover, the films produced by cyclic voltammetry and chronoamperometry carried an anodic load of 3.83 and $4.34 \mathrm{mC} \mathrm{cm}^{-2}$, respectively. The data also showed that the polypyrrole surface roughness was strongly affected by the CG concentration. This study demonstrated the feasibility of producing an alternative conductive biobased film through electrodeposition of $\mathrm{PPy} / \mathrm{CG}$ and gave useful information about its structural and electrochemical properties.

Keywords: composite; polypyrrole; cashew Gum; electrodeposition; conductor.

\section{FULL TEXT}


(C) 2017 The Authors. Published by ESG (www.electrochemsci.org). This article is an open access article distributed under the terms and conditions of the Creative Commons Attribution license (http://creativecommons.org/licenses/by/4.0/). 